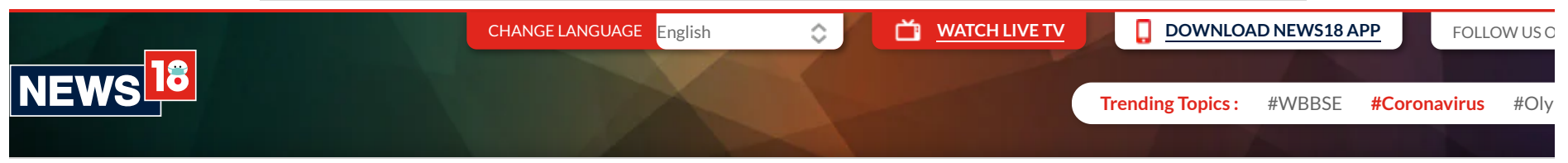

Latest Lifestyle Movies Olympics 2020 Cricket Business Explainers Education-Career Nerolac Games MISSION पामी

HOME 》 NEWS 》 OPINION 》 LIVELIHOODS \& LEARNING MUST NOT TAKE A HIT WHILE CONTAINING COVID-19. HERE'S HOW WE CAN DO IT

\title{
Livelihoods \& Learning Must Not Take a Hit While Containing COVID-19. Here's How We Can Do It
}

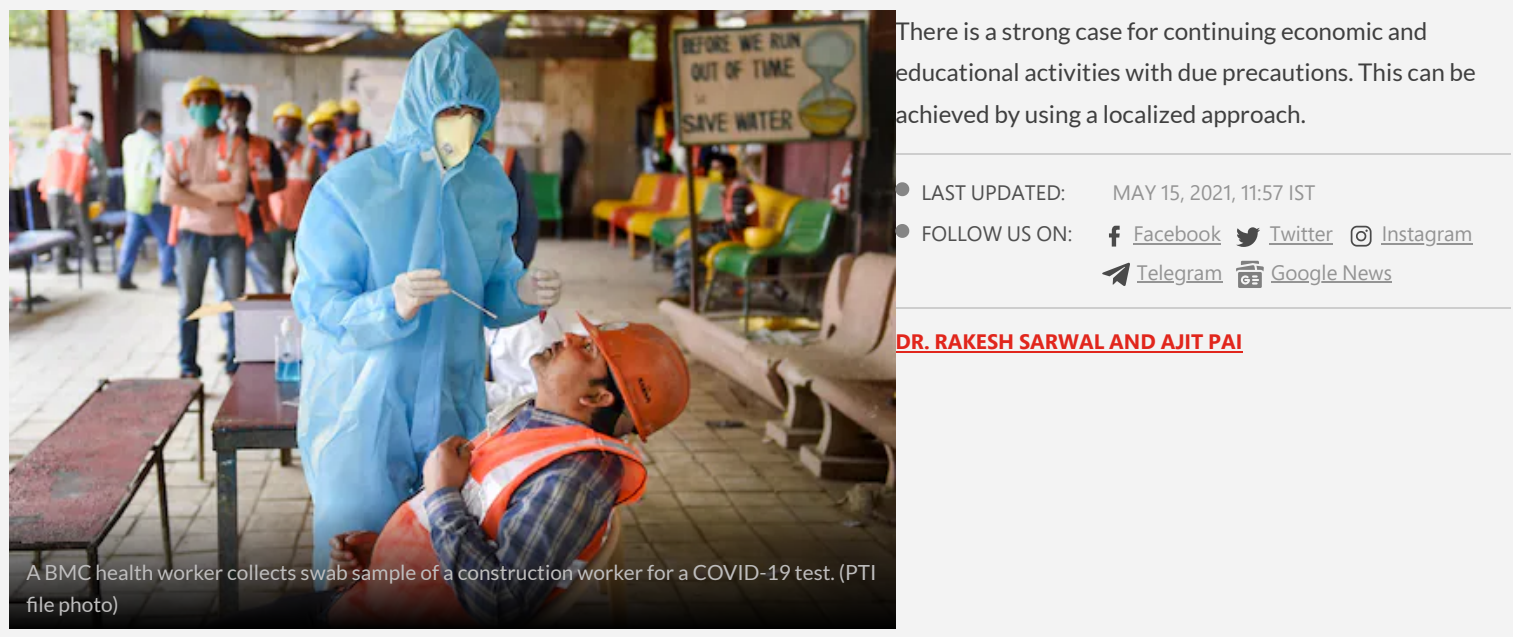

I wake of unprecedented flare-up of COVID cases in the country during the second wave of the pandemic, lockdown is being considered as the last remaining weapon with the government. Early last year, the central government had invoked for the first time the Disaster Management Act, 2005, through a decision of the National Disaster Management Authority under the chairmanship of the Prime Minister, to ensure uniformity in the measures adopted and their implementation. This time around, after learning from the prior nationwide lockdown, state governments are being provided flexibility in lockdowns at their level.

By now, most states and Union Territories (including Delhi) have imposed strict lockdowns, which includes restrictions on opening of shops, movement, public gatherings and industrial activity. Most lockdowns are blanket, irrespective of the extent of COVID infection in the community. India ranks 14th in the COVID-19 Stringency Index globally, with a score of 81.94 (May 7, 2021) out of a maximum possible score of 100.

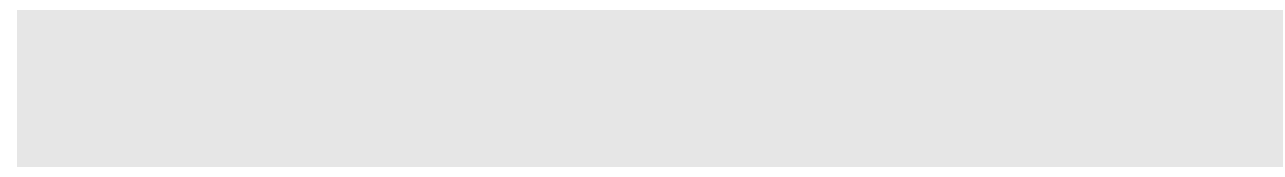

The most ardent proponents of lockdowns admit that they only help delay the onset of cases, generally to flatten the curve to a level that a nations' health care systems can cope with and to provide time to build capacity to required levels when the lockdowns are lifted.

The cost of the 2020 lockdown was steep. India's economy went through a sharp GDP contraction in the quarter ending June 30, 2020, with an unprecedented 24.4 per cent $\mathrm{y} / \mathrm{y}$ decline and led to unemployment rising sharply. Though the government provided significant assistance including greater use of the public distribution system and procurement, direct benefit transfers to some of the most vulnerable, and moratoriums on instalments to repay loans, these were not sufficient to prevent at least three consecutive quarters of well below par growth with some scarring of capacity. A costly but unavoidable trade-off for a country with per capita GDP still below 20 per cent of world average.

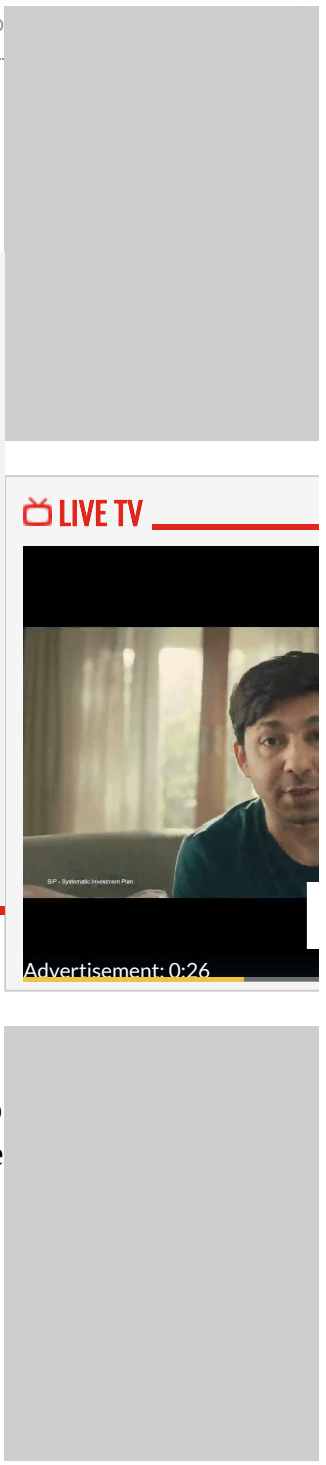

MORE NEWS

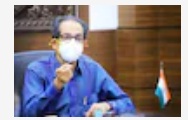

OPINION: under Uddr Scripting a

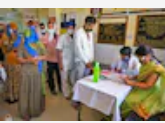

ASHA, AN Workers B COVID in

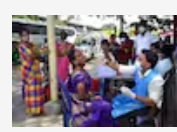

Beyond Ke Models, W for Shared

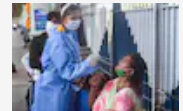

Adequate $\mathrm{C}$ Rooms, Ma How Muml 


$\equiv$ HOME CORONAVIRUS POLITICS INDIA ENTERTAINMENT TECH AUTO BUZZ OPINION VIDEOS
OPINION: How
Maharashtra under
Uddhav Thackeray is
Scripting a Turnaround
in Battle against COVID

Others argue that broad-based lockdowns flatten the wrong curve (GDP), lead to unnecessary human misery, and slow down human progress, and that the situation returns to the inevitable after lockdowns are lifted, suggesting instead that vaccination and awareness among the population is the key to a sustainable management of the pandemic. The question we ask is if there is a way that certain economic and educational activities can continue without increasing the risk of spreading the disease.

\section{A LOCALIZED APPROACH}

An important strategy that became apparent as we learned more about the virus and its behaviour was that a hyper-local approach to control the spread of the infection could be equally or more effective while having far less impact on the economy and livelihoods. It had worked effectively in China, especially Wuhan and Hubei, where the pandemic originated.

Due to a variety of factors, not all of which are well understood, despite the steady opening up of the Indian economy using the hyper-local approach, the first wave of daily new infections peaked in mid-September 2020, and then steadily declined through February 2021, by when the world had multiple vaccination options.

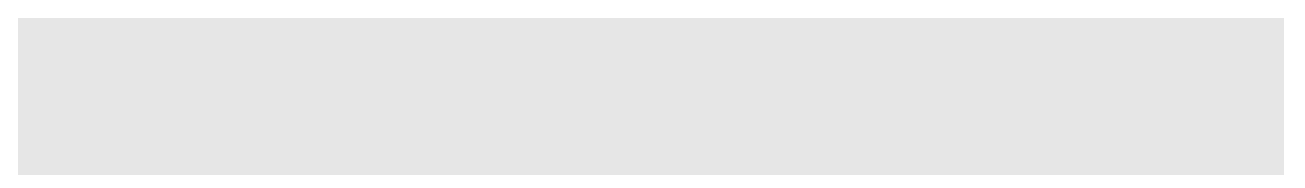

There is a strong case for continuing economic and educational activities with due precautions. This can be achieved by using a localized approach, with each economic and educational campus being treated as a containment zone, whose administration can keep a watch on its residents and workers, and ensure minimized transit into the zone. Organization-wide and repeated use of Rapid Antigen Test (RAT) should be done for all persons at baseline and all visitors to detect infected people early enough before they spread the infection. No person with symptoms of fever etc. may be allowed entry within such zones. The advantage with this test is that its results are available within 15 minutes, can be read with a naked eye, requiring no specialized equipment. ICMR recommends use of RAT in containment zones or hotspots. Any positive result should necessitate immediate home isolation of the person and the chain of contacts.

Using this protocol, along with a systematic geographical zone-by-zone path to universal vaccination, will enable localities to sustain a relatively COVID-free status for as long as precautions are observed. Offices, project sites, educational institutions can ring-fence themselves in this way, while continuing normal activities within. Even in zones of slightly higher incidence, a campus-level approach towards isolation can permit activities to continue with controlled interaction with the world outside. High-incidence zones, or hotspots, can have much stricter restrictions within and with the outside world.

\section{ALLOWING ECONOMIC ACTIVITY}

Construction and infrastructure projects create about five times the jobs for the money spent relative to the average of the Indian economy. To support economic growth while improving India's global competitiveness in manufacturing and services, investment in infrastructure needs to be accelerated. This includes roadways,
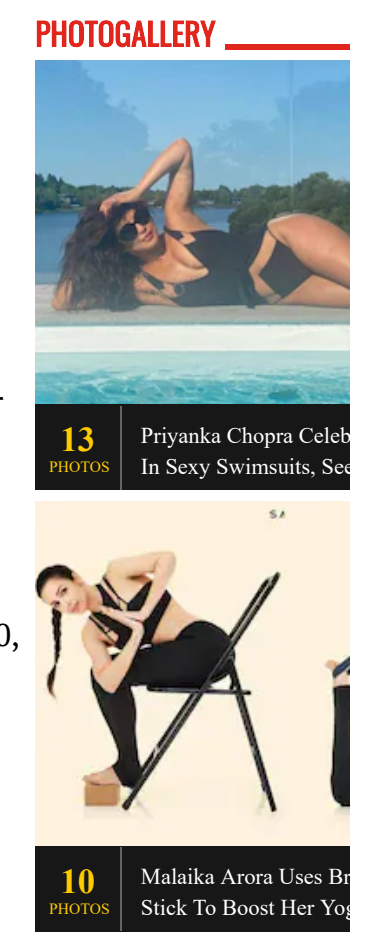

PROMOTED CONTEN

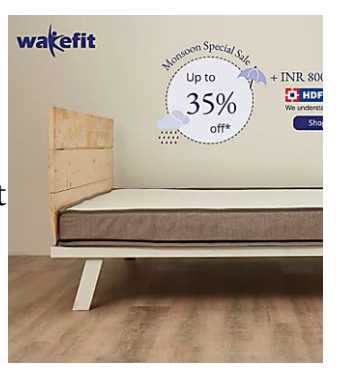

Buy Wakefit Natural Latex mi the upto $35 \%$ discount on ma wakefit.co

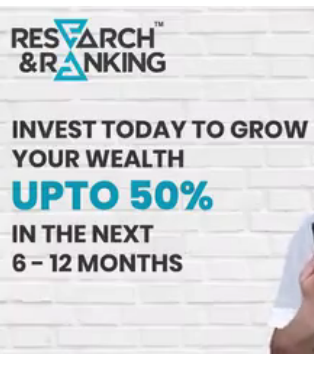

25 Stock Recommendations $t$ Multibagger Portfolio Research \& Ranking 
The largest enterprises in these sectors have the capacity to minimize the probability of workers contracting or spreading the infection, and can be thus allowed to function provided they take necessary steps including tight localization protocols and vaccinations. Import and private procurement of vaccinations for own personnel are a fraction of the cost of project delays for the country and enterprises, and should be encouraged as these are supplementary to government efforts and will contribute to attaining inoculation goals faster.

As the second wave gathers momentum, voices are being raised for lockdown. To slow down projects midway

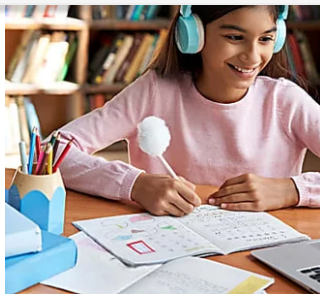
Coding Classes For Age 6-18 Team

campk12.com where contractors have the capacity to minimize the probability of infections (whether through vaccinating or other controls) when the economy needs the jobs and to prolong public inconvenience would be a travesty. Continuing economic activity within enclaves, especially for infrastructure and large building projects, while maintaining appropriate measures to prevent infections will help return our economy to health faster while containing COVID too.

Functional educational institutions are necessary for the progress and mental health of our future generations as well as a source of gainful employment to a very dedicated segment of our workforce. Postponement of examinations, closure of schools and colleges are measures creating material disruptions to progress that could impact generations. In zones of low incidence of the infection, in addition to following the hyper-local protocols suggested, educational activities could be held in open spaces like stadiums, playgrounds, and parks, where possible. Examinations should be a priority, and can be conducted in open areas where possible, while maintaining a safe distance between candidates.

This is a time of difficult choices, making it necessary to take calculated risks keeping the longer term in view. The optimal path is to manage COVID effectively while letting as much economic and educational activity continue that will not lead to an increase in infections.

DISCLAIMER: Dr Rakesh Sarwal is Additional Secretary, NITI Aayog and Ajit Pai is DE, Head of Economics and Finance, NITI Aayog. Views are personal.

Read all the Latest News, Breaking News and Coronavirus News here

- TAGS 2020 COVID-19 PANDEMIC | COVID MANAGEMENT SYSTEM | ECONOMIC ACTIVITIES | LOCALIZED STRATEGY |

- FIRST PUBLISHED: MAY 14, 2021, 15:59 IST

\section{PROMOTED CONTENT}

Wowsome Sale! Buy 1 and Get 1 Free on Wow Skin Science. Use Cod.. Wow Skin Science

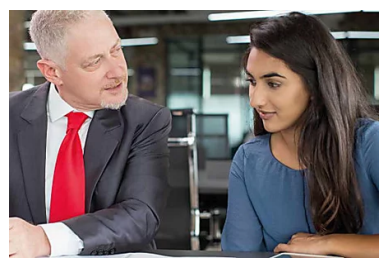

Become a Data Scientist in 11 Months Great Learning

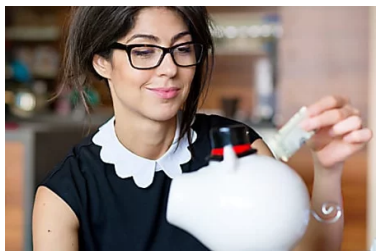

25 Stock

Recommendations to

Create a Multibagger... Research \& Ranking

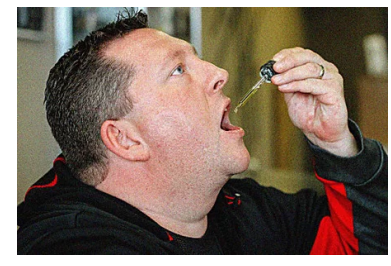

Doctors Baffled: Simple Tip Relieves Years of Joint Pain and Arthriti... Health Today

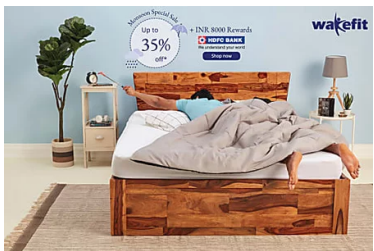

Buy Sheesham Beds with Special

Discount.Upto 35\%off... wakefit.co

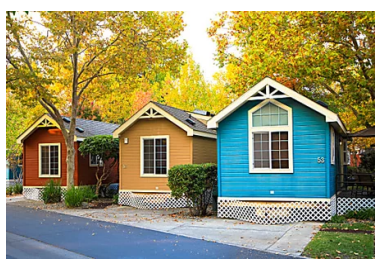

Retirement Villages Near New Delhi Might Have

Seniors Packing Their... Senior Living | Sponsored Listings
Recommended by (-)

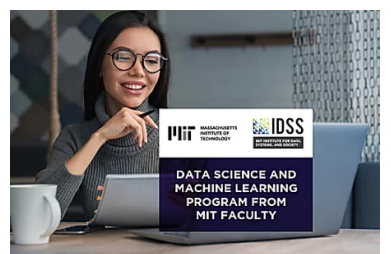

Learn Data Science no tech background required GreatLearning

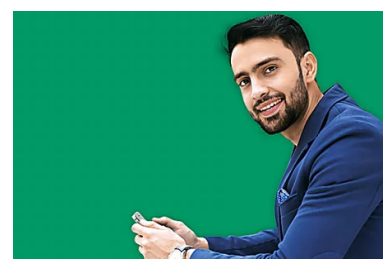

What do top investment firms invest in? CFA ${ }^{\circledR}$ charterholders. CFA Institute 